\title{
Rate of Change in Kermanshahi Kurdish Diphthongs in Word and Sentence Context
}

\author{
Nina HosseiniKivanani, Homa Asadi, Mandana Nourbakhsh \\ Department of Linguistics, Alzahra University, Tehran, Iran \\ Email: Nina.hosseini@student.alzahra.ac.ir
}

Received 12 July 2015; accepted 29 July 2015; published 3 August 2015

Copyright (C) 2015 by authors and OALib.

This work is licensed under the Creative Commons Attribution International License (CC BY). http://creativecommons.org/licenses/by/4.0/

C) (i) Open Access

\begin{abstract}
In order to get a better understanding of diphthongs, as Deterding (2000) and Salbrina (2006) stated, the formant movement can be studied using the rate of change (ROC). Current research has considered the ROC of diphthongs in Kermanshahi Kurdish dialect. In this research, 840 tokens have been considered from speech samples of 20 male/female speakers in word/sentence context. The ROC of the first formant frequency (F1) and the second formant frequency (F2) is studied using Praat version 5.2.34. The results show that $\mathrm{F} 1$ has the most formant movement in /au/ and F1 in /au/, /ai/ has the least formant movement; also, in F2, the vowels of /au/ and /ai/ show the most and least, respectively. Moreover, the ROC values are more in word context than sentence context.
\end{abstract}

\section{Keywords}

Kermanshahi Kurdish Dialect, Diphthongs, Acoustic Analysis, Rate of Change (ROC)

Subject Areas: Linguistics

\section{Introduction}

Kurdish belongs to an Indo-Iranianlanguage family, which is mainly spoken in Turkey, Iraq, Syria and Iran. The three most important classifications of Kurdish dialects are the Northen (Kurmanji), Central (Sorani) and Southern group (Kermanshahi) [1] [2]. The southern group is the main sub-dialects of Kurdish dialects and it is classified into four main dialects: Kermanshahi, Sanjabi, Kalhori and Laki. Kermanshahi, a less studied dialect, is the most spoken dialect in the southern group which is widely spoken in Kermanshah province in the West of Iran [3]. The Kermanshah region is located in Western of Iran.

In relation to the study on Kermanshahi Kurdish dialect, there has been no phonetic study on Kermanshahi Kurdish vowels. To date, all researches up to now have been based on an articulatory description of vowels. Due to lack of investigation in an acoustic field, this study is based on an instrumental analysis of Kermanshahi Kurdish vowels, more specifically, an acoustic description of diphthongs; so to begin to address this subject, this 
paper reviews the onset, offset and ROC of vowels. This work is the first empirical study on this dialect and the principal aim of the present investigation of diphthongs is referred to as "Common Diphthongs" which is described by some scholars (such as [3]-[5]). The physical representation of the vowel sounds of dialects is the basic and vital step of theoretical or empirical studies.

The onset and offset and ROC in F2 are the fixed characteristics in the investigation of diphthongs [6] [7]. [7] [8] asserted in their research that the ROC was an important factor in the differentiation of diphthongs. In studying the vowel quality, [8] offered ROC for F1 because F1 onset and offset didn't give any exact information of diphthongization.

[9] [10] mentioned that ROC had been used as a method for investigation of formant movement in diphthongs and this manner of reaching ROC in better perception of differentiation among diphthongs was useful. Up to now, the ROC of diphthongs has been studied extensively in terms of several languages, which can be seen in English [11] [12], Thai [13], Dutch [14], Sindhi [15], Welsh [16] and Acehnese [17]. About the literature conducted on Kurdish dialect diphthongs, it can only be considered [4] [5] in articulatory phonetics. Previous studies such as [4] [5] have indicated that Kermanshahi Kurdish diphthongs include /ai/, /au/, /au/, /ei/ thus far.

About the ROC investigation of this dialect, it seems that no research exists. So, in this research F1 and F2 (onset, offset and ROC) of diphthongs in this dialect have been studied in word/sentence context among female and male speakers.

\section{Methods}

\subsection{Speakers}

These research participants include 10 male speakers and 10 female speakers in Kermanshahi Kurdish dialect. The average age of the subjects' \pm SD comprises $26.5 \pm 4.61$; the age range of the subjects was between 22 and 35 . Besides, no background of speech disorder was not reported in test by any speaker.

\subsection{Procedures}

The data were recorded in a sound proof room in University of Alzahra. Roland microphone 44,100 Hz was used for recording the voice of speakers. The microphone was diagonally placed at a distance of $20 \mathrm{~cm}$ from the speakers' mouths. The speakers were asked to produce target words in isolation with a pause about three seconds between each word. The recording was repeated three times for each speaker. Then, a Kurdish text was presented to the subjects. Also, they were asked to read out the text once at a normal speech rate. Phonetic tokens were measured and analyzed by using Praat version 5.2.34 [18].

The diphthongs divided into open and closed syllables have been selected in this research. The phonetic sam-

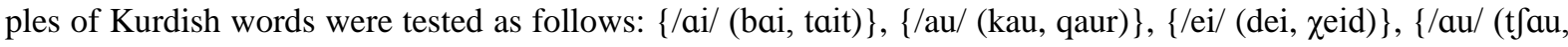
baug) $\}$. The Kurdish text (see Appendix 1) contained 150 words gathered in 860 diphthong tokens in context and word that were acoustically analyzed.

In this research, based on the Gay issue, diphthongs were selected in $20 \%$ and $80 \%$ of vowel length in the spectrogram and it has been used in measuring the formant frequencies in the onset and offset using this model. [9] believed that it was only sufficient using spectrogram to find the onset and the offset of diphthongs. Based on [12], this selection had minimal effect of an adjacent consonants on preceding diphthongs. The following formula which was recommended by the Gay method was used for calculating the ROC values [8]:

$$
\left(F_{\text {loffset }}-F_{\text {lonset }}\right) / \text { duration in seconds }=R O C(\mathrm{~Hz} / \mathrm{s})
$$

\section{Results}

Table 1 shows the average formant frequency values and the standard deviations of F1 and F2 of the onset and offset in the Kermanshahi diphthongs in 4 categories: Male-speakers' Word-context (MSWC), Male-speakers' Sentence-context (MSSC), Female-speakers' Word-context (FSWC) and Female-speakers' Sentence-context (FSSC).

According to Table 1, F1 onset has the least value in /ei/ for the word context of male speakers and F1 onset has the most amount in /ai/ for FSWC. Based on Table 1 /ai/ has the most value in F1 offset for FSSC and /ei/ has the least value in F1 offset for MSWC. F1 onset and offset is more among female speakers than among male 
Table 1. Means and Standard deviations (in parenthesis) for F1 and F2 (onset and offset) of diphthongs by Kermanshahi speakers.

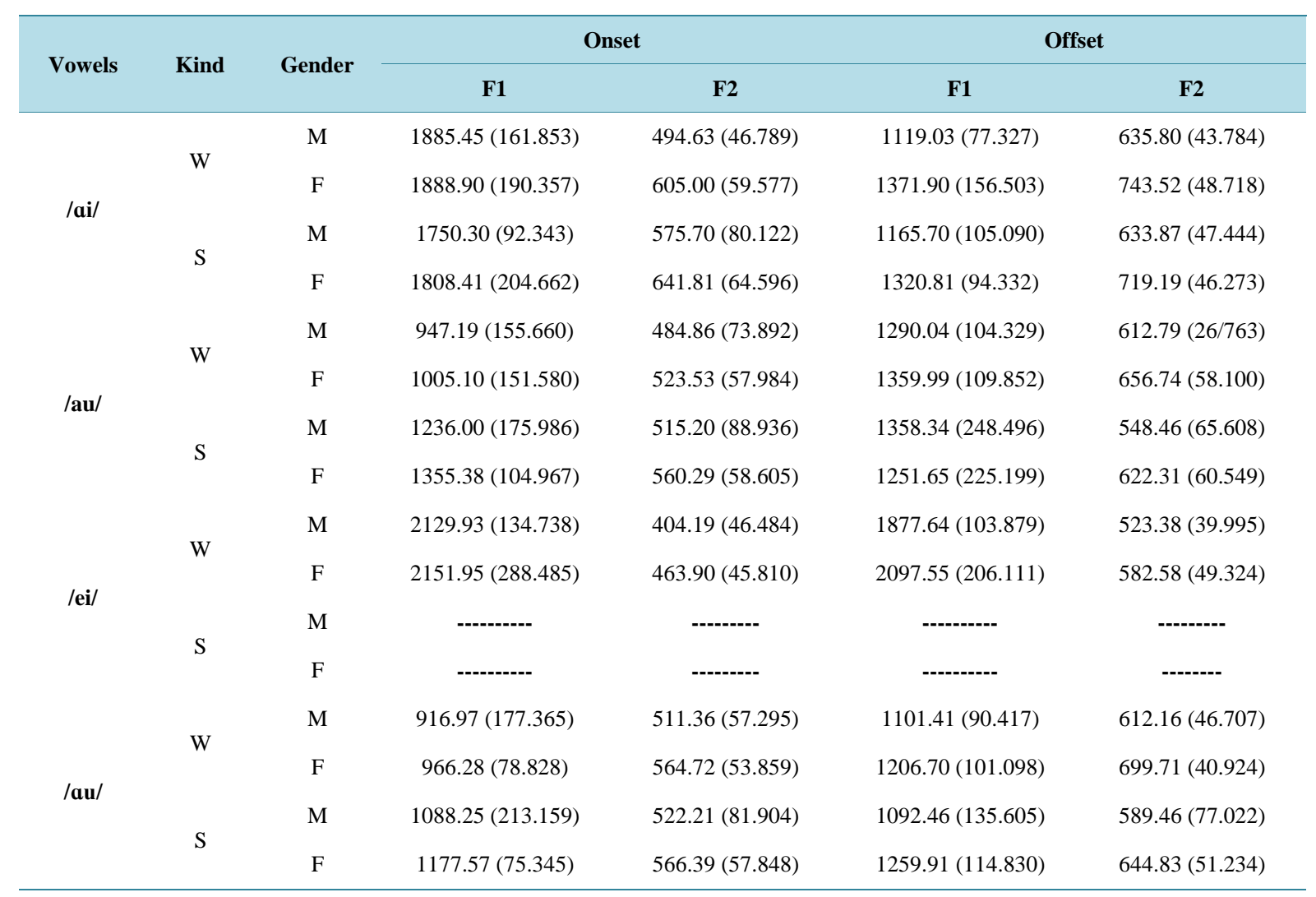

$\mathrm{W}$ = word; $\mathrm{S}$ = sentence; $\mathrm{M}$ = male speaker; $\mathrm{F}$ = female speaker.

speakers. Based on the average reported, F1 has reduced from onset to offset, because F1 in movement of open vowels has reduced to closed vowels.

According to the reported values, there is a decline from F1 onset to F1 offset, since F1 is declined in the transition of diphthongs from open vowels towards closed vowels.

Based on this table, F2 onset and offset of /ei/ in FSWC has the most value. The least amount of F2 onset in MSSC is observed in /au/. The least F2 offset related to /au/ is also reported in MSWC. Based on the investigation of the average of F2 onset and offset, F2 onset /au/, /au/ and /au/ has less frequency than monophthongs of /a/ and /a/. Offset also follows the same pattern of frequency. [19] had mentioned the decrease of F2 onset on diphthongs in his research.

The average of F1 and F2 in onset and offset of each diphthong of the vowel space in Figure 1 (see Appendix 2) is drawn to provide visual representation of diphthongs with respect to the vowel space of monophthongs in the background for comparison. In Figure 1, the end of the arrow reveals the onset and offset of diphthongswhere thediphthong formants (F1 and F2) are plotted against the formants of Kermanshahi Kurdish monophthongs. The F1-F2 vowel space of seven monophthongs [i, e, a, a, o, u, y] of the four groups are from previous acoustic analysis of vowels [20].

It is expected that the onset of /au/ and /ai/ be close to /a/, /au/ to /a/ and /ei/ to /e/ and also their offset moves towards to /u/ and i/, respectively. As shown in Figure 1, the position of onset and offset of diphthongs in the vowel space almost does not exist near any monophthongs of Kermanshahi Kurdish dialect. Based on descriptive statistics of F1 and F2 (onset and offset) of Table 1, the results are as follows:

MSWC: F1 onset and offset of /au/ and /au/, in MSWC is reduced in comparison to F1 of monophthongs. F1 offset of /ai/ and /ei/ has increased, and the onset of /ai/ has reduced and the onset of /ei/ has increased respectively. The increase of F1 means that the offset position of /ei/ and /ai/ is much more open than monophthongs, as shown in Figure 1 (Appendix 2). Moreover, the study of F2 shows that the onset and offset of /au/ and /ei/ 
have decreased and onset of /ai/ and /au/ has increased and offset of/ai/ and /au/has decreased in comparison to monophthongs. According to the figure, the movement path of onset of /au/ is not close to /a/ and offset of /ai/ is not close to the monophthong $/ \mathrm{i} /$.

MSSC: F1 onset and offset of /ai/ in sentence context is increase and onset and offset of /au/, /au/ are decrease and increase, respectively. F2 of /au/ and /au/, are also decreased and in the onset of /ai/ is increased and in the offset is decreased in comparison to the seven monphthongal vowels of kermanshahi Kurdish dialect. In Figure 1 (Appendix 2), the offset of /ai/ moves towards /e/ and the onset of /au/ does not begin in close to /a/.

FSWC: According to the results of monophthongs, F1 onset and offset F1 of /ei/ have increased and /au/, /au/ have decreased and onset of /ai/ has decreased and offset of /ai/ has increased. In F2, FSWC onset and offset of /au/ have decreased and onset of /ai/ and /ei/ has increased and offset of /ai/ and /ei/ has decreased. The F2 ROC of /au/ in onset has decreased and offset has increased. In the figure of FSWC, only onset of /au/ does not move towards /a/ and is placed close to /e/. The vowels /ai/, /ei/ and /au/ movement path changes from /a/, /a/ to /i/ and $/ \mathrm{u} /$.

FSSC: F1onset and offset of /ai/, /au/ and /au/ have decreased and increased respectively while F2 of onset and offset of the three mentioned vowels have decreased. When the position of onset and offset of diphthongsis compared with the monophthongs position, it is obvious that /ai/ moves towards /e/ from /a/. The onset of /ai/ is not placed close to the position of Kermanshahi Kurdish monophthongs while the offset of this diphthong is placed adjacent to $/ \mathrm{u} /$.

Based on the analysis of the average of F2 onset and offset, it could be declared that F2 onset of /au/, /ai/ and /au/ has a lower frequency in comparison to /a/ and /a/. This trend has also taken place in the offset. According to the picture of MSSC and FSSC, the onset and offset of diphthongs in comparison to the vowel space are centralized. As shown in Diagram 1, formants frequency of diphthongs changes from onset to offset of each vowel.

According to Figure 1, F1 and F2 of offset of /ai/, /ei/ is not close to /i/ and only /ei/ in word context of male speakers and word context of female speakers is close to /i/. According to F1 and F2 of monophthongs (Figure 1 in Appendix 2) and in comparison with offset of /ai/, it is shown that F1 in MSWC, MSSC, FSWC and FSSC moves towards /e/. Based on Figure 1 (Appendix 2), the diphthongs movement of /ai/, /ei/ and /au/ changes from /a/, /e/ to /i/, /u/. Just the movement of /au/ has been from the position close to /e/ to the position near /u/ in Figure 1.

The positions of F1 and F2 of the diphthongs in the acoustical vowel space are not close to the positions of the seven monphthongal vowels. The formant movement in /au/ and /au/mainly begins from open vowel and ends to closed back vowel, shown in Figure 1, in /ai/ and /ei/ the formant movement begins from open and mid vowel and ends to closed front vowel. [8] [21] believe that the target diphthong is different from the described vowels which are used for the transcription of diphthongs. It means that diphthongs do not exactly begin and end with any of the monophthongs. With regard to the diphthongs onset and offset, Holbrook and Fairbanks's study [22] reveals that onset and offset has their own phonological representation, independent of monophthongs. The figure gives information to support this finding of Kermanshahi Kurdish dialect.

In Table 2, the average of F1 and F2 ROC values for closing diphthongs of Kermanshahi are reported. In the table below, standard deviation is placed in parentheses.

According to Table 2, F1 ROC of closing diphthongs, /ai/, /au/, /ei/ and /au/ a negative value is attained. The reason is the diphthong movement from open vowel position to closed vowel position. Therefore, F1 will be reduced. F1 ROC in closing vowels is expected to be negative [12]. Regardless of the negative value of each mean, in F1 ROC, /au/ (MSSC) shows the most formant movement in vowel height change compared to the other vowels. The lowest formant movement is (the lack of change in vowel height) related to /au/ (MSWC) and /ai/ (MSSC). F2 ROC in closing diphthongs, /ai/ MSSC has the most ROC in the diphthongs of Kermanshahi Kurdish dialect and the lowest value is also related to /au/ in FSWC. The negative value in F2 ROC shows a backward movement. As indicated in Table 2, the average of formants frequency of ROC in sentence context in comparison to word context has increased.

To compare the average ROCs of the F1 and F2 between word and sentence context, independent samples t-test were carried out. The investigation of F1 and F2 ROC between word/sentence in independent-t-test in the results of F1 ROC indicates that no significant difference between word and sentence of/ai/ $(\mathrm{F} 1 \mathrm{ROC}: \mathrm{t}(175)=$ -2.17, $\mathrm{p}=0.051)$, /au/ (F1 ROC: $\mathrm{t}(156)=1.294, \mathrm{p}=0.197)$ and $/ \mathrm{au} /(\mathrm{F} 1 \mathrm{ROC}:-\mathrm{t}(808)=-0.623, \mathrm{p}=0.536)$, has been reported.Based on F1 ROC, it can be concluded that no significant difference between word and sentence context exists. Examining the F2 ROC in word and sentence context, the results show that /ai/ (F2 ROC: $\mathrm{t}(80)=-4.175, \mathrm{p}=0.000)$, /au/ (F2 ROC: $\mathrm{t}(151)=-4.175, \mathrm{p}=0.000)$ and $/ \mathrm{au} /(\mathrm{F} 2 \mathrm{ROC}: \mathrm{t}(56)=-3.083, \mathrm{p}=$ 0.000). 
Table 2. Average F1 and F2 ROC values for diphthongs of male and female speakers in word/sentence.

\begin{tabular}{|c|c|c|c|c|}
\hline \multirow{2}{*}{ Vowels } & \multirow{2}{*}{ Kind } & \multirow{2}{*}{ Gender } & F1 ROC & F2 ROC \\
\hline & & & Mean (SD) & Mean (SD) \\
\hline \multirow{4}{*}{$/ \mathbf{a i} /$} & \multirow{2}{*}{$\mathrm{W}$} & M & $-725.67(334.276)$ & 3834.51 (704.788) \\
\hline & & F & -793.55 (590.627) & 2783.84 (1226.402) \\
\hline & \multirow{2}{*}{$\mathrm{S}$} & $\mathrm{M}$ & $-538.29(628.415)$ & $5151.90(1346.831)$ \\
\hline & & $\mathrm{F}$ & $-639.32(406.704)$ & 3806.61 (1787.240) \\
\hline \multirow{4}{*}{ /au/ } & \multirow{2}{*}{$\mathrm{W}$} & M & $-570.62(382.755)$ & -695.77 (1191.267) \\
\hline & & F & -756.69 (296.998) & -747.07 (1024.648) \\
\hline & \multirow{2}{*}{ S } & M & $-871.87(1012.705)$ & 867.59 (3221.259) \\
\hline & & $\mathrm{F}$ & $-670.13(663.312)$ & $1236.26(2706.631)$ \\
\hline \multirow{4}{*}{ /ei/ } & \multirow{2}{*}{$\mathrm{W}$} & M & -688.37 (295.675) & $1450.09(526.517)$ \\
\hline & & F & $-661.48(379.282)$ & 290.92 (1664.918) \\
\hline & \multirow{2}{*}{ S } & M & ------- & ------- \\
\hline & & $\mathrm{F}$ & ------- & ------- \\
\hline \multirow{4}{*}{$/ \mathbf{a u} /$} & \multirow{2}{*}{$\mathrm{W}$} & M & $-530.96(273.513)$ & $-971.18(1027.409)$ \\
\hline & & F & $-726.04(278.501)$ & $-1294.90(459.626)$ \\
\hline & \multirow{2}{*}{ S } & M & $-558.10(559.541)$ & $-106.22(2369.355)$ \\
\hline & & $\mathrm{F}$ & $-620.17(310.266)$ & $-610.40(580 / 289)$ \\
\hline
\end{tabular}

(Standard deviations in parentheses).

As a result, the differentiation of F2 ROC is valid betweenword and sentence. The average of the data shows the increasing in ROC within a sentence than a word. [9] in his own research asserted that in clear speech, value of ROC in word context is less than sentence and continue speech, respectively.

\section{Conclusion}

In detecting F1 ROC of diphthongs is obtained by negative amounts because diphthongs have been moved from open vowels position to closed vowels position. Thus, F1 is reduced. Based on the result, each of the four vowels tends to be closed. On the basis of the data obtained, F2 ROC asserts that /ai/ exhibits the most ROC value among male speakers in sentence context and /au/ exhibits the least value of F2 ROC. The negative value in /au/ and /au/ indicates a backward in vowel space. While positive value shows formant movement from back to front in /ai/ and /ei/.

\section{References}

[1] Allison, C. (2007) The Kurds are Alive: Kurdish in Iraq. In: Postgate, J.N., Ed., Languages of Iraq: Ancient and Modern, Cambridge University Press, Cambridge, 135-158.

[2] Gutner, M.M. (2003) The A to Z of the Kurds. Scarecrow Pres, Lanham.

[3] Ranjbar, V. (2009) Kermanshahi Kurdish Grammar, Kermanshah. Taghbustan Publication, Kermanshah. (In Persian)

[4] Shirzaditabar, B. (1996) Description of Kermanshahi Kurdish Dialect. MA Thesis, University of Tehran, Tehran. (In Persian)

[5] Ganbari, L. (2010) The Comparison of Kermanshahi Kurdish and Laki Dialect. MA Thesis, Azad University of Tehran, Iran. (In Persian)

[6] Collier, R., Bell-Berti, F. and Raphael, L.J. (1982) Some Acoustic and Physiological Observations on Diphthongs. Language \& Speech, 25, 305-323. 
[7] Gay, T. (1970) A Perceptual Study of American English Diphthongs. Language \& Speech, 13, 65-88.

[8] Gay, T. (1968) Effect of Speaking Rate on Diphthong Formant Movements. Journal of Acoustical Society of America, 44, 1570-1573. http://dx.doi.org/10.1121/1.1911298

[9] Deterding, D. (2000) Measurements of the /eI/ and /əo/ Vowels of Young English Speakers in Singapore. In: Brown, A., Deterding, D. and Low, E.L., Eds., The English Language in Singapore: Research on Pronunciation. Singapore Association for Applied Linguistics, Singapore, 93-99.

[10] Salbrina, S.H. (2006) The Vowels of Brunei English: An Acoustic Investigation. English World-Wide, 27, $247-264$. http://dx.doi.org/10.1075/eww.27.3.03sha

[11] Lehiste, I. and Peterson, G.E. (1961) Transitions, Glides, and Diphthongs. Journal of Acoustical Society of America, 33, 268-277. http://dx.doi.org/10.1121/1.1908638

[12] Tsukada, K. (2008) An Acoustic Comparison of English Monophthongs and Diphthongs Produced by Australian and Thai Speakers. English World-Wide, 29, 194-211. http://dx.doi.org/10.1075/eww.29.2.05tsu

[13] Roengpitya, R. (2007) A New Look on Diphthongs in Thai. Paper Presented at the 13th Annual Meeting of the Southeast Asian Linguistics Society, SEALS XIII, Canberra, 231-237.

[14] Jacobi, I. (2009) On Variation and Change in Diphthongs and Long Vowels of Spoken Dutch. Doctoral Dissertation, University of Amsterdam, Amsterdam.

[15] Keerio, A., Dhomeja, L.D., Shaikh, A.A. and Malkani, Y.A. (2011) Comparative Analysis of Vowels, Diphthongs and Glides of Sindhi. Signal \& Image Processing: An International Journal (SIPIJ), 2, 109-119. http://dx.doi.org/10.5121/sipij.2011.2409

[16] Mayr, R. and Davies, H. (2011) A Cross-dialectal Acoustic Study of Monophthongs and Diphthongs of Welsh. Journal of the International Phonetic Association, 41, 1-25. http://dx.doi.org/10.1017/S0025100310000290

[17] Pillai, S. and Yusuf, Y.Q. (2012) An Instrumental Analysis of Acehnese Oral Vowels. Language \& Linguistics, 13, 1029-1050.

[18] Boersma, P. and Weenink, D. (2007) PRAAT: Doing Phonetics by Computer (Version 5.2.34) [Computer software]. http://www.fon.hum.uva.nl/praat/

[19] Lee, S., Potamianos, A. and Narayanan, S. (2013) Developmental Aspects of American English Diphthong Trajectories in the Formant Space. Journal of the Acoustical Society of America, 133, 3337-3341. http://dx.doi.org/10.1121/1.4805617

[20] HosseiniKivanani, N. (2014) Acoustic Analysis of Kermanshahi Kurdi Vowels System. MA Thesis, Alzahra University, Tehran. (In Persian)

[21] Ladefoged, P. (2006) A Course in Phonetics. Thomson, Los Angeles.

[22] Holbrook, A. and Fairbanks, G. (1962) Diphthong Formants and their Movements. Journal of Speech, Language, and Hearing Research, 5, 38-58. http://dx.doi.org/10.1044/jshr.0501.38 


\section{Appendix 1}

\section{Kurdish Story}

ruzi la nau ruzgar je baugi bui ke se kor daft, wa naue malek bahman, malek ahmad wa malek dzamfir. bauge i se kora wa koregani wet agar men merdem bas ta se fau ła sar qaurem negabani bein. koreganif weten bafa ta je ruz baugian merd. bera butfkala weta beragani ke bain ta faui jakigman betfuda sar qaur baugeman wa negabani bed. bera butfkala wet men

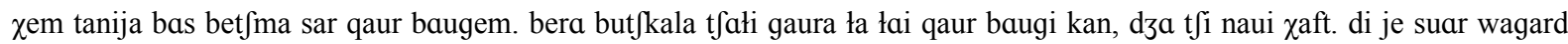
t farwa kauig wa duro tie waro qaur baugi ta bai dozi bekai. malek dzamfir deł wa darya da suar kofto dza t farwagan berda

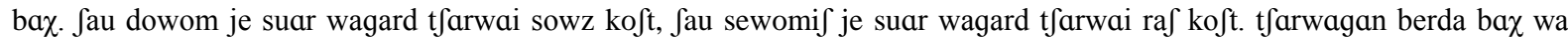
basadiana dar. dza wa beragani wet wati hyt $\int$ bawer nakerden. dzarkifik hato dzar kifa ke fai se dod dire ke wagarde jek dusen. t fałi qaura wa durian kani wet har kas baz berd ?aw das buda zawai men. bera malek dzamfir t fi baru łai dodagan. dod butfkala niada pe ftio hata ri. mardem haz kerden, har weten bezani ja kia. wagard. t farwai kau hat, dod wasatine hawerd. dza wa beragani wet. dodagan nifanijan da. dod gouraga da berai qaura,wasatina bera wastina dza dod butfkala aria $\chi$ aui $\chi a z d$.

\section{Appendix 2}

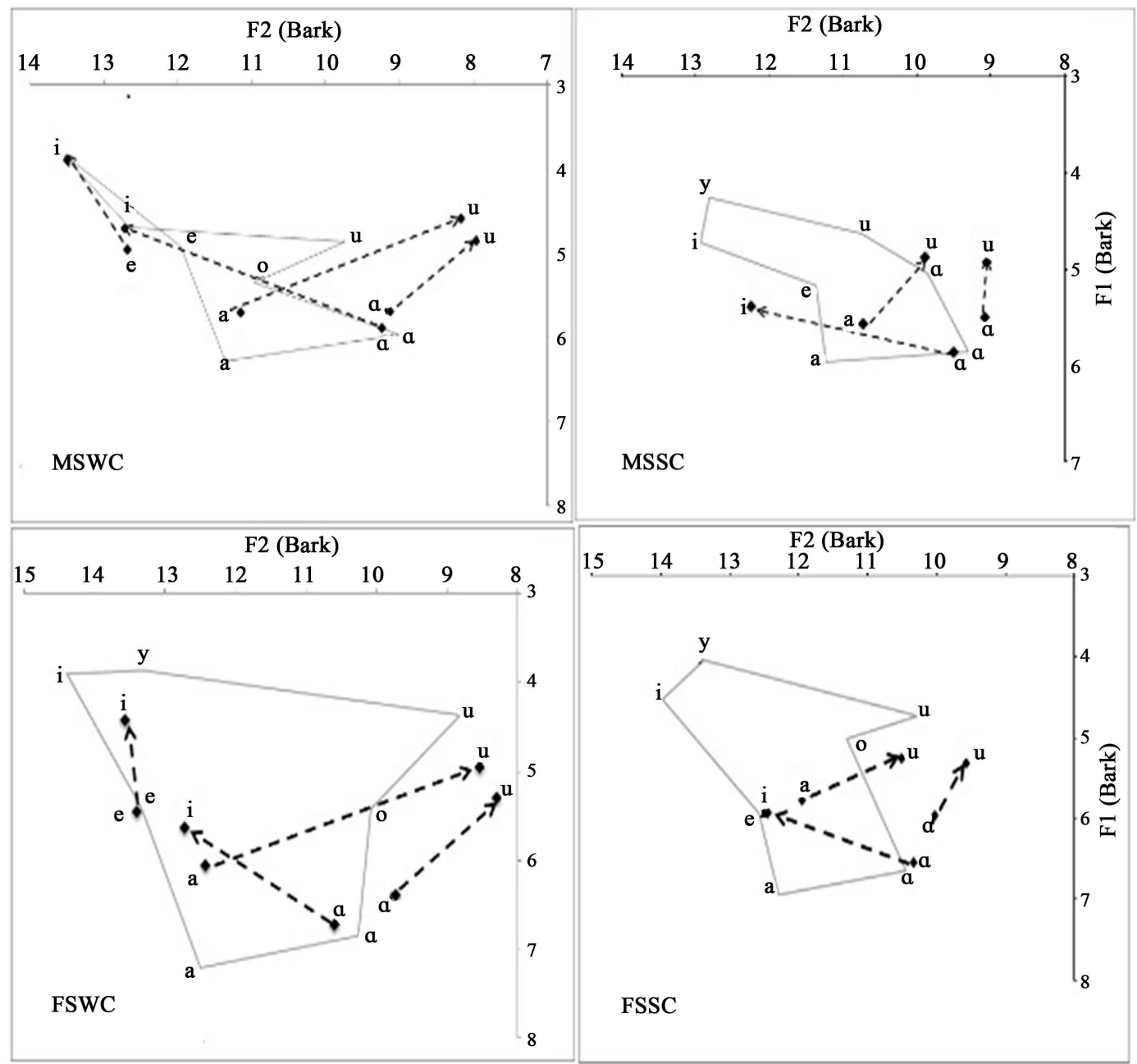

Figure 1. Trajectory of diphthongs in 4 categories by Kermanshahi speakers: MSWC (up-right), MSSC (upleft), FSWC (down-right) and FSWC (down-left). 